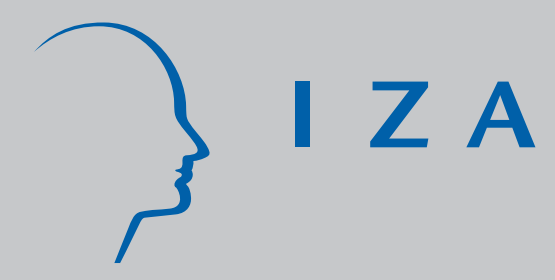

IZA DP No. 3676

Management Compensation and Firm-Level Income Inequality

Anders Frederiksen

Odile Poulsen

September 2008 


\title{
Management Compensation and Firm-Level Income Inequality
}

\author{
Anders Frederiksen \\ Hoover Institution, Stanford University, \\ Aarhus School of Business and IZA \\ Odile Poulsen \\ University of East Anglia

\section{Discussion Paper No. 3676 September 2008}

\author{
IZA \\ P.O. Box 7240 \\ 53072 Bonn \\ Germany \\ Phone: +49-228-3894-0 \\ Fax: +49-228-3894-180 \\ E-mail: iza@iza.org
}

Any opinions expressed here are those of the author(s) and not those of IZA. Research published in this series may include views on policy, but the institute itself takes no institutional policy positions.

The Institute for the Study of Labor (IZA) in Bonn is a local and virtual international research center and a place of communication between science, politics and business. IZA is an independent nonprofit organization supported by Deutsche Post World Net. The center is associated with the University of Bonn and offers a stimulating research environment through its international network, workshops and conferences, data service, project support, research visits and doctoral program. IZA engages in (i) original and internationally competitive research in all fields of labor economics, (ii) development of policy concepts, and (iii) dissemination of research results and concepts to the interested public.

IZA Discussion Papers often represent preliminary work and are circulated to encourage discussion. Citation of such a paper should account for its provisional character. A revised version may be available directly from the author. 


\begin{abstract}
Management Compensation and Firm-Level Income Inequality

In recent decades, most developed countries have experienced a simultaneous increase in income inequality and management compensation. In this paper, we study the relation between management compensation and firm-level income dynamics in a general equilibrium model. Empirical estimation, of the model's key parameters show that the rising management premium is indeed the main driving force behind the observed increase in income inequality. This is the case even when other potential sources such as technological progress and skillbiased technological change are taken into account. We also show that a rising management premium produces income distribution dynamics at the firm level which are similar to those observed at the market level, i.e. rising income inequality overall as well as within and between education groups.
\end{abstract}

JEL Classification: J3, J6, M5, O3

Keywords: income inequality, two-sector search model, skill-biased technological change, personnel data

Corresponding author:

Anders Frederiksen

Department of Economics

Aarhus School of Business

Silkeborgvej 2

DK-8000 Aarhus C

Denmark

E-mail: afr@asb.dk

\footnotetext{
"We thank Sara Connolly, Tor Eriksson, Christina Gathmann, Bo Honoré, John Kennes, Eddie Lazear, Paul Oyer, Ilya Segal, Eric Smith, Elöd Takáts, Niels Westergaard-Nielsen and numerous seminar participants for their comments. Anne Raaby Olsen has provided valuable research assistance. We acknowledge financial support from The British Academy.
} 


\section{Introduction}

In recent decades, most developed countries have experienced increasing income inequality (OECD, 2007). At the same time, management compensation has risen sharply, see Abowd and Bognanno (1995), Murphy (1999), and Piketty and Saez (2006). In this paper, we investigate the consequences of rising management compensation for firm-level income inequality. Our main finding is that a rising management premium produces income distribution dynamics at the firm-level that are similar to those observed more generally at the market level. ${ }^{1}$ That is, a higher management premium increases both within- and between-education group income inequality, besides adding to overall income dispersion. We also show that alternative sources to increasing income inequality such as technological progress and skill-biased technological change are unable to produce similar income distribution dynamics.

We investigate the link between management compensation and income inequality using a general equilibrium framework similar to Pissarides (1994). Our analysis follows Albrecht and Vroman (2002) and Gautier (2002). Albrecht and Vroman explore an economy with heterogeneous workers and jobs. A key aspect of their model is that jobs have skill requirements. This implies that low-skilled individuals are unproductive in jobs requiring high skills. In contrast, highly skilled workers can take a job of any type but they are more productive in jobs requiring high skills. Mis-matched workers do not search for better jobs. The model in Gautier (2002) is similar to Albrecht and Vroman but Gautier allows highly educated employees to perform on-the-job search. Our model can be seen as an extension of Gautier (2002) in that we allow both low and high-educated employees to perform on-the-job search. This extension is important because we can use it to explain the empirical observation that there is a skill mix in all job types, i.e. low- and highly-educated employees work in both the management and non-management sector of the firm. This has important implications for the income distribution.

We estimate the model's key parameters using seven years of monthly personnel records (1997 to 2003) from the main production site of an international pharmaceutical company. The advantage of these data compared to traditional labor market data sets is that the data contains information on job assignment, that is, if the worker is employed in management or nonmanagement. This additional information is important because it allows us

\footnotetext{
${ }^{1}$ See Autor and Katz (1999) and Autor, Katz and Kearney (2005) for a detailed discussion of the income distribution at the market level and decomposition methods.
} 
to identify the rapidly growing management premium as the source of the increasing firm-level income inequality overall as well as within- and betweeneducation groups. This result cannot be identified using conventional labor market data.

Our empirical analysis also assists in identifying technological progress and management-biased technological progress (i.e. technology shocks increasing the relative productivity of management employees) as empirically important. In contrast, our analysis questions the empirical importance of skill-biased technological change. The reason is that the change in the income gap between highly- and low-educated employees, conditional on the changes in the management premium, is insignificant. However, unconditionally the between-education group income gap is increasing, but this only reflects that highly educated employees have a higher representation in management and therefore are more likely to harvest the increasing management premium. Overall, the technology shocks have implications for the equilibrium income distribution. Technological progress increases income for all employees and thereby shifts the income distribution to the right, whereas managementbiased technological progress only increases income for managers. Thus we can identify the growing management premium as the source of the increasing income inequality observed in the firm.

The information on job assignment that we use to identify the central role of the management premium for the observed increase in income inequality comes at a cost; namely the limitation to one firm. For this reason, we do not claim that our empirical results are representative for the economy. But our findings show that rising management compensation is a prime candidate for explaining the observed increase in income inequality at the market level because of the income distribution dynamics it creates at the firm-level, such as the ability to increase both within- and between-group income inequality.

Our findings complement other research on the income distribution. Piketty and Saez (2006) find that top income shares are rising in the United States, the United Kingdom, and Canada from the mid-1980s. They also document that the increase is mainly a labor income phenomenon and not due to business or capital income. Other papers such as Murphy (1999) Hall and Murphy (2003), Murphy and Zábojník (2004 and 2007) and Frydman (2005) focus on CEO compensation in the United States and report similar findings. Our results show that to understand the changes in the income distribution, focus should be broadened beyond CEOs as it is the earnings progression of managers (and not just the CEO) that drives the increasing income inequality. This result is important because it stresses that the structure of the firm should be modelled when studying changes in the income distribution.

The outline of the paper is as follows. In the next section, we present the 
theoretical model and the equilibrium is established in Section 3. In Section 4, we present the data and document preliminary evidence of the changes in the income distribution. We present the empirical results in Section 5. Finally, Section 6 summarizes and concludes. Proofs and additional regressions are relegated to the Appendix.

\section{The Model}

Consider a firm with a management $(M)$ and non-management $(N)$ sector that faces a labor force of $\Xi$ workers. The workers employed by the firm are members of the internal labor market denoted by $I$, the remaining individuals constitute the external labor force, $E$. The size of the total labor force is normalized to unity, i.e. $\Xi=I+E=1$. All workers are distinguished by an observable level of education where the proportion $\pi$ of the workers is low-educated and the remaining $1-\pi$ is highly-educated. Highly-educated workers will be referred to as $H$-workers while low-educated workers will be referred to as $L$-workers. We shall use the notation $k \in\{H, L\}$ and $j \in\{N, M\}$.

When the firm opens up a vacancy, the type is determined ex-ante. Thus, the job search behavior is as follows. First, for reasons explained below, individuals have the highest productivity in management jobs. This implies that employees with the required level of education from both the non-management part of the internal labor market $\left(i_{k N}\right)$ and the external labor market $\left(e_{k}\right)$ apply for management vacancies $\left(v_{k}\right)$. Second, employees currently working in management $\left(i_{k M}\right)$ have no incentives to search for a new job, hence only individuals in the external labor market search for non-management vacancies $\left(v_{N}\right)$.

Workers and vacancies meet each other randomly according to a matching function that is increasing in its argument, concave, and homogenous of degree 1 . The matching processes between jobs and workers in management are represented by

$$
x_{k M}=x_{k M}\left(v_{k}, e_{k}+i_{k N}\right)=\left(v_{k}\right)^{\alpha}\left(e_{k}+i_{k N}\right)^{1-\alpha},
$$

and in non-management by

$$
x_{N}=x_{N}\left(v_{N}, e_{L}+e_{H}\right)=\left(v_{N}\right)^{\alpha}\left(e_{L}+e_{H}\right)^{1-\alpha} .
$$

The labor market flows are illustrated in Figure 1. Individuals in the external labor market search for both non-management and management jobs in the firm. If an individual gets a job in the non-management sector 


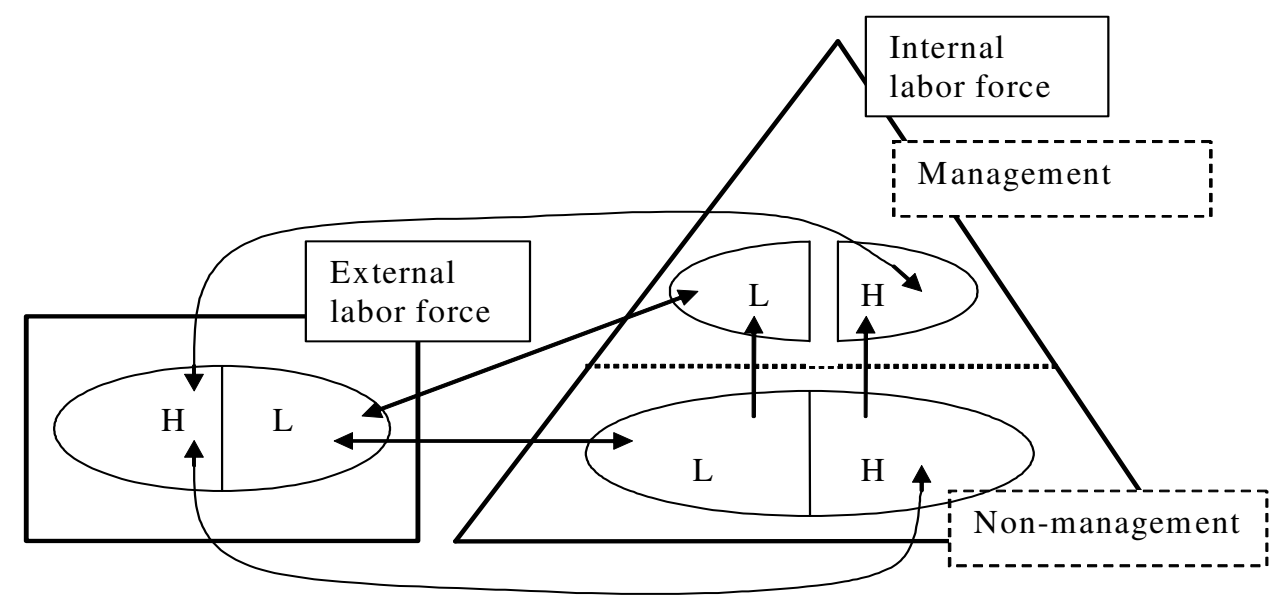

Figure 1: Flow diagram

of the firm, he has an option to be promoted. Since jobs in management have education requirements, both low- and highly-educated employees are promoted. All employees have an exogenous separation risk, hence there are flows from both the management and non-management sector back into the external labor market.

A worker's output is denoted by $y_{k j}$. We make two assumptions about the workers productivity. First, highly-educated workers are more productive than low-educated workers because schooling gives the workers a higher production capacity. Second, we assume, as do Lucas (1978) and Rosen (1982) that workers in non-management jobs have limited discretion over resources and hence are less productive than employees in management jobs who control resources. Thus $y_{L N}<y_{H N}<y_{L M}<y_{H M}$.

Finally, we denote the probability that a $k$-type job meets a worker of type $k$ by

$$
\begin{aligned}
q_{k M}\left(\theta_{k}\right) & =\frac{x_{k M}}{v_{k}}=\frac{x_{k M}\left(\theta_{k}, 1\right)}{\theta_{k}} \\
q_{N}\left(\theta_{N}\right) & =\frac{x_{N}}{v}=\frac{x_{N}\left(\theta_{N}, 1\right)}{\theta_{N}}
\end{aligned}
$$

The terms $\theta_{k}$ and $\theta_{N}$ represent labor market tightness and are defined as: $\theta_{k}=v_{k} /\left(e_{k}+i_{k N}\right)$ and $\theta_{N}=v_{N} /\left(e_{L}+e_{H}\right)$. Similarly, we denote the probability that a worker of type $k$ encounters a vacancy of type $k$ by $p_{k M}$ and 
the rate at which a worker meets a non-management job by $p_{N}$. It follows that

$$
\begin{aligned}
p_{k M}\left(\theta_{k}\right) & =\frac{x_{k M}}{e_{k}+i_{k N}}=x_{k M}\left(\theta_{k M}, 1\right) \\
p_{N}\left(\theta_{N}\right) & =\frac{x_{N}}{e_{L}+e_{H}}=x_{N}\left(\theta_{N}, 1\right) .
\end{aligned}
$$

\subsection{Payoff Functions and Wage Determination}

The firm maximizes the present discounted value (PDV) of expected profits and the individual maximizes the PDV of the expected income stream. The firm decides if a particular vacancy should be opened or not. The individual assesses if the job offer received is sufficiently attractive given the alternative options such as other employment or continued job search. When the worker and the firm meet, they bargain over the wage. In the following, we describe these processes.

\subsubsection{The Firm}

The firm advertises three different types of jobs: a vacancy in non-management and two vacancies in management. These require different levels of education. Since the non-management vacancy can be filled with a worker of any education level, the firm will in practice employ up to four different employee types: low-educated in non-management, highly-educated in non-management, loweducated in management, and highly-educated in management. These types generate different levels of profits since they differ in their productivities and - as will be shown below - different costs.

Let us denote the expected PDV of having a vacant non-management job by $V_{N}$. The expected PDV of the vacancy depends on the potential worker's productivity. For this reason, we denote the PDV of a vacancy filled with an employee of type $k$ by $J_{k N}$.

Under perfect competition the valuation of a vacant non-management job is such that the cost $r V_{N}$ (where $r$ is the discount rate) equals the rate of return. Recalling that the job is filled by a highly-educated or a low-educated worker with probability $q_{N}$, the rate of return can be written as the difference between the cost of the vacant non-management job, $c_{N}$, and the expected average return generated by having the job filled. The average return from having a low-educated or a highly-educated worker in the job is equal to the sum of the returns generated by low-educated workers and the returns generated by highly-educated workers, weighted by the relative population 
size. From this it follows that equation (1) will be satisfied in equilibrium:

$$
r V_{N}=q_{N}\left[\frac{e_{L} J_{L N}+e_{H} J_{H N}}{e_{L}+e_{H}}-V_{N}\right]-c_{N} .
$$

Using the same intuition, the valuation of a non-management job filled by a worker of type $k$ can be written such that the cost, $r J_{k N}$, equals the return. In this case, the return is the output produced by the worker, $y_{k N}$, minus $w_{k N}$, the wage paid to the worker. In addition to this, the eventual loss of revenues that occur if the worker and the firm separate, which happens with probability $s$, and the potential loss if the worker finds a job in the management sector must be added. We therefore have

$$
r J_{k N}=y_{k N}-w_{k N}+s\left(V_{N}-J_{k N}\right)+p_{k M}\left(V_{N}-J_{k N}\right) .
$$

We can now derive the remaining expected PDVs for the firm in the same way. The expected income streams of the management vacancies, $V_{k M}$, are:

$$
r V_{k M}=q_{k M}\left(J_{k M}-V_{k M}\right)-c_{k M}
$$

where $c_{k M}$ are the vacancy costs.

Finally, the expected profit from recruiting a worker of type $k$ to a management job, $J_{k M}$, is given by:

$$
r J_{k M}=y_{k M}-w_{k M}+s\left(V_{k M}-J_{k M}\right)
$$

where $w_{k M}$ is the wages paid to an employee of type $k$ working in management.

\subsubsection{The Worker}

A worker of type $k$ earns $w_{k N}$ when employed in non-management and $w_{k M}$ when working in management. For simplicity, we normalize an employee's income in the external labor market to zero.

Let $E_{k}$ be the present discounted value of the expected income stream for a type $k$ worker in the external labor market. The individual may move to a job either in non-management or in management. The first event occurs with probability $p_{N}$. The worker would then earn the present discounted value of the expected income stream $W_{k N}$ until a job in management arrives or a separation from the firm occurs. If the individual instead gets a job in management (which occurs with probability $p_{k M}$ ), the present discounted value of the expected income stream is $W_{k M}$ until separation. In sum, $E_{k}$ is equal to the expected gain from a change of state:

$$
r E_{k}=p_{N}\left(W_{k N}-E_{k}\right)+p_{k M}\left(W_{k M}-E_{k}\right) .
$$


The payoff to a worker in non-management, $W_{k N}$, is given by the wage, $w_{k N}$, the risk premium against separation, and the option value of being promoted:

$$
r W_{k N}=w_{k N}+s\left(E_{k}-W_{k N}\right)+p_{k M}\left(W_{k M}-W_{k N}\right),
$$

where $W_{k M}$ is the expected income stream in a management job.

Employees already working in management do not search for a new job, but they face the separation risk, $s$. Thus, the payoff to a management job is

$$
r W_{k M}=w_{k M}+s\left(E_{k}-W_{k M}\right) .
$$

\subsubsection{Wage Determination}

Wages are determined by Nash bargaining where a proportion of the match value $(0<\beta<1)$ is allocated to the worker and the remaining part to the firm. We follow Gautier (2002) and assume the following employee disagreement payoffs:

$$
r D_{k N}=s\left(E_{k}-D_{k N}\right)+p_{k M}\left(W_{k M}-D_{k N}\right),
$$

where $D_{k N}$ is the disagreement payoff for employees in the external labor market bargaining for a non-management job. The disagreement payoffs capture two important aspects. First, negotiation may fail (with probability $s$ ), in which case the employee returns to the external labor market and earns $E_{k}$. Second, while bargaining for a non-management job, the worker may find a more attractive job in management (with probability $p_{k M}$ ) and thus receive the payoff associated with a management jobs $W_{k M}$. The disagreement payoffs for workers bargaining for a management job are similar:

$$
r D_{k M}=s\left(E_{k}-D_{k M}\right) .
$$

\section{Equilibrium}

We derive the steady state equilibrium by imposing two assumptions. First, the labor market flows are stable and the flow of a particular employee type into a sector equals the flow out. Second, all profit opportunities in the market are exhausted. That is, $V_{N}=0$ and $V_{k M}=0$. The equilibrium is derived in the Appendix and the equilibrium income distribution is presented in Proposition (1).

Proposition 1 In equilibrium:

a) Wages are proportional to productivity: $w_{k, j}=\beta y_{k, j}$

b) The income distribution is: $w=w_{k, j}$ with probability $i_{k, j} / I$ 
Proof. See the Appendix.

\subsection{Interpretation}

Technology shocks alter the equilibrium income distribution. In this section, we discuss the consequences of technological progress, skill-biased technological change, and management-biased technological change (i.e. a shock which alters the relative productivity of management employees) for income inequality. We also propose an empirical strategy for identification of the various shocks. Our empirical findings (presented in the next section) show that while technological progress shifts the income distribution right, the observed increase in income inequality is explained by management-biased technological progress because it increases the management premium, and hence widens the income distribution. Further, skill-biased technological progress empirically plays an insignificant role.

To advance our understanding of the changes in income inequality, note first that in Proposition 1 wages are proportional to productivity. Thus, using the wage of low-educated employees in the non-management sector as the reference group and denoting their wages as $w_{L N}=\beta y_{L N}=\beta y$, we can write $w_{H N}=\beta \mu_{1} y, w_{L M}=\beta \mu_{2} y$ and $w_{H M}=\beta \mu_{3} y$, where the productivity differentials are ranked such that $1<\mu_{1}<\mu_{2}<\mu_{3}$. We also assume the following:

$$
\begin{aligned}
\frac{\mu_{1}}{c_{N}} & <\frac{\mu_{2}}{c_{L M}}<\frac{\mu_{3}}{c_{H M}}, \\
\mu_{1} & <2 \\
\mu_{1} & <\frac{(1-\alpha) \mu_{2}}{\alpha c_{L M}}, 0<\alpha<1, \\
\frac{\mu_{2}}{(\pi)^{\frac{1-\alpha}{\alpha}} c_{L M}} & <\frac{\mu_{3}}{c_{H M} .}
\end{aligned}
$$

Using the $(\mu, y)$-notation, it follows that income inequality within the group of low-educated employees is $w_{L M} / w_{L N}=\mu_{2}$ and within the group of highly educated employees it is $w_{H M} / w_{H N}=\mu_{3} / \mu_{1}$. It can also be established that income inequality between highly and low-educated employees increases in $\mu_{1}$ and $\mu_{3}$ but decreases in $\mu_{2}$. This implies that managementbiased technological progress (i.e. an increase in $\mu_{2}$ and $\mu_{3}$ ) leads to higher within-education group inequality. Further, because the management sector empirically is dominated by highly educated employees, management-biased technology progress increases between-education group income inequality. 
Alternatively, skill-biased technological progress increasing the relative productivity or highly educated employees (i.e. $\mu_{1}$ and $\mu_{3}$ ) clearly increases between-education group income inequality but has no effect on within-group inequality. Finally, technological progress increasing $y$ has no consequences for within- and between-education group income inequality.

\section{Definition 1 (Technology shocks):}

1) Technological progress increases the productivity of all employees equally

2) Skill-biased technological progress increases the relative productivity of highly educated employees relatively to low-educated employees

3) Management-biased technological progress increases the relative productivity of managers relative to non-management employees.

An important implication of the derived relation between relative wages and productivity is that the employees' relative productivity can be estimated directly from a standard Mincer wage equation:

$\left.\left.\ln \left(w_{i t}\right)=\alpha+t+\mu_{1 t}^{*} 1_{\left(w_{i t}=w_{H N}, t\right.}\right)+\mu_{2 t}^{*} 1_{\left(w_{i t}=w_{L M}, t\right.}\right)+\mu_{3 t}^{*} 1_{\left(w_{i t}=w_{H M}, t\right.}+X_{i t}^{\prime} \delta+\epsilon_{i t}$,

where $1_{(.)}$is an indicator function, $a$ is a constant, $t$ and $X$ control for time and other factors, $\epsilon$ is an error term, and $\delta$ and the $\mu^{\prime} s$ are parameters.

The point estimates obtained from the regression can be used to predict the expected log-wages for the different employee subgroups. For instance, $\ln \hat{w}_{L N t}=\hat{\alpha}+\hat{t}+X_{t}^{\prime} \hat{\delta}$ and $\ln \hat{w}_{H N t}=\hat{\alpha}+\hat{t}+\hat{\mu}_{1 t}^{*}+X_{t}^{\prime} \hat{\delta}$. Thus,

$$
\ln \hat{w}_{H N t}-\ln \hat{w}_{L N t}=\hat{\mu}_{1 t}^{*} \text {. }
$$

Recall that

$$
\frac{w_{H N t}}{w_{L M t}}=\mu_{1 t} \Leftrightarrow \ln \left(\frac{w_{H N t}}{w_{L N t}}\right)=\ln \mu_{1 t} \Leftrightarrow \ln w_{H N t}-\ln w_{L N t}=\ln \mu_{1 t} .
$$

Hence, combining equations (10) and (11) we get

$$
\hat{\mu}_{1 t}^{*}=\ln \mu_{1 t} \Leftrightarrow \mu_{1 t}=\exp \left(\hat{\mu}_{1 t}^{*}\right) .
$$

Furthermore, note that $\ln \hat{w}_{L N t+1}-\ln \hat{w}_{L N t}=t$. Similar links can be made between the model's remaining parameters and the Mincer equation. Thus, regression (9) can be used to identify the technology shocks and therefore be used to identify the driving forces behind the observed changes in the income distribution. 


\section{The Data}

Seven years of monthly personnel records from the main production size of an international pharmaceutical company are used in the empirical analysis. The average employment in the firm over the period 1997 to 2003 is 6175 persons, and the share of management workers in the firm is close to 4 percent. $^{2}$ The promotion probability is almost 2 percent per year and the yearly separation rate is 3.5 percent.

The full data set consists of 519,016 observations. These data contain information about the employee's age, gender, tenure, education, job assignment, and wages. The observations with missing information (mainly caused by lacking information on education) are deleted, which leaves us with a sample of 488,282 observations. This is the sample used in the analysis below.

\begin{tabular}{lc}
\hline \hline & $\begin{array}{c}\text { Mean } \\
\text { (standard deviation) }\end{array}$ \\
\hline Age & 39.532 \\
& $(8.946)$ \\
Tenure & 7.796 \\
& $(7.266)$ \\
Gender (woman = 1) & 0.550 \\
Education (high = 1) & 0.348 \\
& \\
Observations & 488,282 \\
\hline \hline
\end{tabular}

Table 1: Descriptive statistics, 1997-2003.

The descriptive statistics are presented in Table 1. The firm employs 55 percent women and the average employee is 40 years old. These individuals have on average 8 years of tenure. The firm is operating in a segment where product development is crucial for survival. This implies that a large proportion of the employees are engaged directly in research. In addition, the production process is highly automated, and in order to meet the strict requirements of the FDA (Food and Drug Administration) product testing

\footnotetext{
${ }^{2}$ We only consider permanent full-time employment in this analysis which corresponds to 91.76 percent of the individuals employed. In addition, the executive management (CEO, executive vice presidents and senior vice presidents) is excluded due to lack of information on the compensation package for these individuals. Including these individuals in the analysis would only have strengthend our conclusions. For recent surveys on executive compensation, see Murphy (1999) and Hall and Murphy (2003).
} 
is an essential part of production. This explains the high education level in the firm where 35 percent of the firm's employees have a college degree or above. In the sequel, we term individuals with education levels below a college degree as low-educated and the remaining part as highly-educated.

A preliminary look at the (real) income structure in the firm reveals some interesting features. Table 2 shows the average income and the relative size of the four subgroups: low-educated non-management, highly-educated nonmanagement, low-educated management, and highly-educated management. As expected, income increases with education level and rank. Furthermore, it can be seen that all four groups experience real income progression over the 7-year period, but the growth rates differ substantially across groups. Most pronounced is the 25 percent income growth for low-educated employees in management. In contrast, income only increases by 4 percent for loweducated employees in non-management. Similar tendencies can be seen for highly educated individuals. These preliminary results indicate that the income gap between management and non-management employees increased substantially over the period.

\begin{tabular}{lcccc}
\hline \hline \multicolumn{4}{c}{ Employee subgroup } \\
& \multicolumn{4}{c}{} \\
\cline { 2 - 5 } & $\begin{array}{c}\text { Low-educated } \\
\text { Non-management }\end{array}$ & $\begin{array}{c}\text { Highly-educated } \\
\text { Non-management }\end{array}$ & $\begin{array}{c}\text { Low-educated } \\
\text { Management }\end{array}$ & $\begin{array}{c}\text { Highly-educated } \\
\text { Management }\end{array}$ \\
\hline 1997 & 25,953 & 36,561 & 40,430 & 55,241 \\
& $(3,802)$ & $(9,740)$ & $(7,400)$ & $(11,904)$ \\
& 26,319 & 37,076 & 45,512 & 58,180 \\
1998 & $(3,869)$ & $(9,788)$ & $(8,886)$ & $(12,754)$ \\
& 26,502 & 37,816 & 46,053 & 57,685 \\
2000 & $(3,836)$ & $(10,261)$ & $(10,184)$ & $(11,376)$ \\
& 26,582 & 38,178 & 46,630 & 58,717 \\
2001 & $(3,874)$ & $(10,445)$ & $(11,231)$ & $(11,850)$ \\
& 26,771 & 37,940 & 49,439 & 59,911 \\
& $(4,248)$ & $(10,217)$ & $(11,234)$ & $(13,259)$ \\
2002 & 26,737 & 37,018 & 49,584 & 59,111 \\
& $(4,262)$ & $(9,296)$ & $(12,479)$ & $(12,612)$ \\
& 26,926 & 37,656 & 50,689 & 60,104 \\
Real income & $(4,136)$ & $(8,942)$ & $(12,169)$ & $(12,035)$ \\
growth 1997-2003 & $3.75 \%$ & $3.00 \%$ & & $8.80 \%$ \\
& & & $25.37 \%$ & \\
\# observations & 317,234 & 150,425 & & 19,521 \\
\hline \hline
\end{tabular}

Tabel 2: Real income progression, 1997 to 2003. 


\section{Income Inequality}

In this section, we investigate how income inequality has changed between 1997 and 2003. The technological shocks causing the income distribution to change are identified by estimating (9). The empirical evidence shows that both general technological progress (i.e. $t$ increases) and managementbiased technological progress (i.e. $\mu_{2}, \mu_{3}$ increase) are empirically important but skill-biased technological change plays an insignificant role. It is also the case that while general technological progress shift the income distribution to the right, the increase in income inequality is due only to management-biased technological progress. These changes imply that all workers experience real income progression of 1.2 percent and that the management premium increases by as much as 8 percent.

\subsection{Empirical Analysis}

The results from estimation of (9) are presented in Table 3. In the first model, only education-rank categories are included. The point-estimate of $\mu_{1}^{*}$ is 0.32 which implies that the estimated productivity differential between low- and highly-educated employees in non-management is 32 percent. The point-estimates for $\mu_{2}^{*}$ and $\mu_{3}^{*}$ reveal productivity differentials between loweducated in non-management and low- and highly-educated employees in management of 56 percent and 79 percent, respectively. Adding further information to the model, i.e. including time dummies and demographic and tenure variables, reduces the point-estimates of $\mu_{2}^{*}$ and $\mu_{3}^{*}$ slightly but overall the highly significant productivity differentials persist.

The models presented in Table 3 estimate the average productivity differentials. To assess the importance of changes in relative productivity over time for the income distribution, a model similar to Model 3 in Table 3 is estimated for the two years 1997 and 2003. The point estimates from these regressions are used together with the characteristics of the workforce in 1997 to predict the wages for the two years. The 1997 workforce characteristics are used in both predictions to avoid employee composition effects. This reveals that the standard deviation of the predicted income distributions increases from 0.22 to 0.25 between the two years; a result that is shown in Figure 2 where kernels for the two predicted distributions are presented. This documents that the income distribution is affected significantly by the changes in relative productivity over the period 1997 to 2003 . 


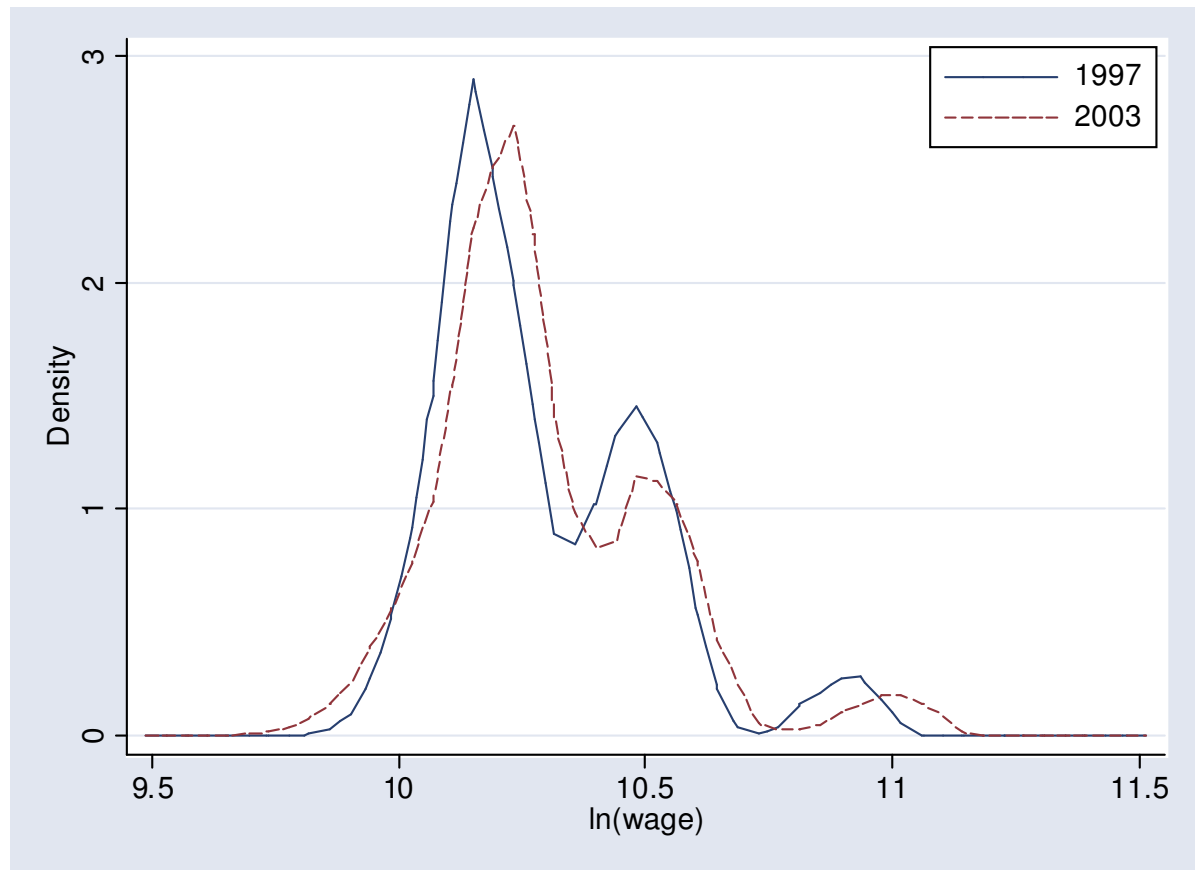

Figure 2: Predicted income distributions for 1997 and 2003.

\begin{tabular}{|c|c|c|c|}
\hline & (1) & (2) & (3) \\
\hline $\begin{array}{l}\text { Low-educated in } \\
\text { Non-management }\end{array}$ & - & - & - \\
\hline $\begin{array}{l}\text { Highly-educated in } \\
\text { Non-management }\end{array}$ & $\begin{array}{c}0.320 \\
(0.007)\end{array}$ & $\begin{array}{r}0.320 \\
(0.007)\end{array}$ & $\begin{array}{c}0.326 \\
(0.006)\end{array}$ \\
\hline $\begin{array}{l}\text { Low-educated in } \\
\text { Management }\end{array}$ & $\begin{array}{c}0.562 \\
(0.049)\end{array}$ & $\begin{array}{c}0.563 \\
(0.050)\end{array}$ & $\begin{array}{c}0.483 \\
(0.050)\end{array}$ \\
\hline $\begin{array}{l}\text { Highly-educated in } \\
\text { Management }\end{array}$ & $\begin{array}{c}0.788 \\
(0.009)\end{array}$ & $\begin{array}{c}0.788 \\
(0.009)\end{array}$ & $\begin{array}{c}0.715 \\
(0.009)\end{array}$ \\
\hline Constant & $\begin{array}{l}10.171 \\
(0.003)\end{array}$ & $\begin{array}{l}10.151 \\
(0.003)\end{array}$ & $\begin{array}{c}9.073 \\
(0.092)\end{array}$ \\
\hline $\begin{array}{l}\text { Demographic and } \\
\text { tenure variables } \\
\text { Time dummies }\end{array}$ & $\mathrm{NO}$ & $\mathrm{NO}$ & YES \\
\hline R-squared & 0.316 & 0.317 & 0.398 \\
\hline
\end{tabular}

Note: Standard errors are clustered with respect to individuals. The demographic and tenure variables used in the regression are: gender, age, age squared, tenure and tenure squared.

Table 3: Mincer wage equations. 


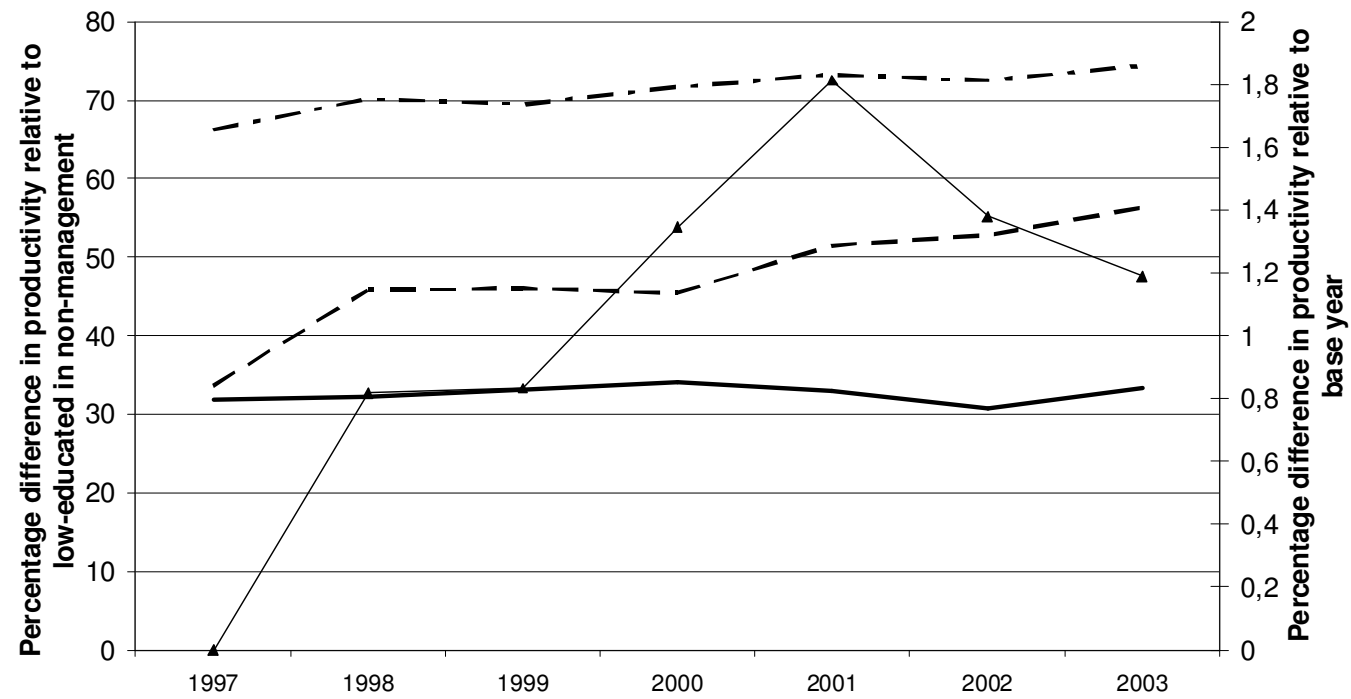

$-\mu 1^{*}$ : highly-educated in non-management $--\mu 2^{*}$ : low-educated in management
$--\mu 3^{*}$ : highly-educated in management $\rightarrow-$ t: general productivity growth (right axis)

Figure 3: Changes in general and relative productivity

To fully accommodate the shifts in the parameters, we estimate a model which includes dummies for belonging to a particular employee subgroup, time dummies and interaction terms between employee subgroup and time dummies. The results of this estimation are presented in Figure $3 .^{3}$ First, the general productivity level is increasing for all employee subgroups from 1997 and up to 2001 and declining thereafter (i.e. $t$ increases until 2001). This implies that the general productivity level in 2003 is at the same level as in 2000. Over the period, the general productivity level increases with 1.2 percent. The development in relative productivity can also be read from Figure 3. $\mu_{1}$ (the relative productivity between highly- and low-educated employees in non-management) has increased by 1.4 percent. This change is small compared to the increasing differences between non-management and management workers. $\mu_{3}$ (the differential between highly-educated in management and low-educated in non-management) is altered by 8 percent and the increase in $\mu_{2}$ (the differential between low-educated in management and non-management) is as high as 23 percent.

The results show clear evidence of technological progress due to the significant increase in the parameter $t$. In addition, they show that the relative pro-

\footnotetext{
${ }^{3}$ The regression is presented in the Appendix.
} 
ductivity across employees is altered. Productivity progression has been particularly strong for management employees (both highly- and low-educated) but also the productivity of highly-educated workers in non-management has increased relatively to low-educated in non-management. These results indicate that both skill- and management-biased technological progress are potentially important.

To shed more light on the relative importance of skill- and managementbiased technological change, we estimate an additional set of regressions. In the first model presented in Table 4, dummies for having a high education and being a manager are included. Highly educated are estimated to be 33 percent more productive than low-educated and managers are estimated to produce 40 percent more than non-managers. In Model 2, the change over time in the education dummy is identified by adding interaction terms between being highly educated and time dummies. The results show an increase of 2 percent. When a similar regression is estimated for the changes in the management dummy, it reveals a substantial increase of 8 percent. Finally, in Model 4 the changes over time in both dummies are estimated simultaneously. The results show that the growth in the education dummy becomes insignificant, while the growth in the management dummy remains high and at a level of 8 percent. Thus, conditional on the relative changes occurring between management and non-management employees the productivity gap due to education remains constant. Unconditionally, however, the education productivity gap is increasing, but this only reflects that employees with higher educations have a higher representation in management and for that reason are more likely to capture the increasing management productivity.

In sum, the empirical analysis reveals that management-biased technological change and technological progress are important whereas skill-biased technological change plays an insignificant role. The implications for the income distribution are twofold. First, technological progress increases the overall income level and thus shifts the income distribution right. Second, management-biased technological progress increases the management premium which moves the upper tail of the distribution further to the right. This leads to the conclusion that the increased income inequality observed in the firm is due to rapid growth in the relative income of management employees caused by management-biased technological progress. 


\begin{tabular}{lcccc}
\hline \hline & Model (1) & Model (2) & Model (3) & Model (4) \\
\hline Constant & $9.075(0.092)$ & $9.079(0.091)$ & $9.077(0.092)$ & $9.079(0.091)$ \\
Low education & - & - & - & - \\
High education & $0.325(0.006)$ & $0.312(0.006)$ & $0.325(0.006)$ & $0.318(0.006)$ \\
(HE) & - & - & - & - \\
Non-management & $0.395(0.010)$ & $0.395(0.010)$ & $0.340(0.013)$ & $0.344(0.013)$ \\
Management (M) & & & & \\
& & $0.008(0.003)$ & & $0.003(0.003)$ \\
HE*1998 & $0.015(0.004)$ & & $0.012(0.005)$ \\
HE*1999 & $0.026(0.005)$ & & $0.021(0.005)$ \\
HE*2000 & $0.015(0.008)$ & & $0.011(0.008)$ \\
HE*2001 & $-0.002(0.012)$ & & $-0.011(0.014)$ \\
HE*2002 & $0.022(0.009)$ & & $0.013(0.009)$ \\
HE*2003 & & & $0.042(0.006)$ & $0.040(0.007)$ \\
M*1998 & & & $0.032(0.011)$ & $0.025(0.011)$ \\
M*1999 & & $0.051(0.013)$ & $0.038(0.014)$ \\
M*2000 & & $0.072(0.014)$ & $0.066(0.016)$ \\
M*2001 & & & $0.073(0.015)$ & $0.080(0.019)$ \\
M*2002 & & & & $0.076(0.016)$ \\
M*2003 & & & & \\
& & & 0.389 & 0.390 \\
R-squared & & & & \\
\hline
\end{tabular}

Note: Standard errors are clustered with respect to individuals. Year dummies are used in all regressions and the demographic and tenure variables are: gender, age, age squared, tenure and tenure squared.

Table 4: Mincer wage regressions.

\section{Conclusion}

The purpose of this paper has been to link the rapid growth in management compensation to the increasing income inequality observed in most developed countries. Our analysis shows that changes in management compensation generate income distribution dynamics at the firm level which mimics those observed at the market level. In particular, rising management compensation increases income inequality overall and produces higher within- and betweeneducation group inequalities.

It is an interesting finding that the increasing inequality between education groups is a consequence of rapid growth in management productivity and not because of changes related to education per se. This finding should attract the attention of education economists and stimulate further research on the effect of firm structure on the returns to education.

The results presented in this paper have important policy implications beyond those traditionally discussed when income inequality is rising. The reason is that women traditionally have a low representation in management, see Booth, Francesconi and Frank (2003). Consequently, when increasing 
income inequality is driven by rapid growth in management compensation, the earnings gap between men and women widens. Thus, although it is an open question (to an economist) whether rising income inequality is good or bad, rising income inequality driven by growing management compensation has the negative side effect of increasing gender differences.

Finally, our analysis emphasizes the importance of understanding the internal workings of a firm when studying the changes in the income distribution. The main reason is that the structure of the firm, i.e. the division into a management and a non-management sector, produces a gap in earnings due to the management premium which is unexplained in conventional studies of the income distribution. We show by modeling the firm structure explicitly, that a large part of the (otherwise) unexplained income dispersion can be contributed to the allocation of employees across hierarchical levels. Thus, the present study emphasizes that a deeper understanding of the internal firm processes helps to advance our understanding of income distribution dynamics.

\section{References}

[1] Abowd, J., and M. Bognanno, 1995, International differences in executive and managerial compensation, in: Richard Freeman and Lawrence Katz, Differences and Changes in Wage Structures, National Bureau of Economics Research (NBER), University of Chicago Press

[2] Albrecht, J., and S. Vroman, 2002, A Matching Model With Endogenous Skill Requirements, International Economic Review, 43: 283-305.

[3] Autor, D. H., and L. F. Katz, 1999, Changes in the Wage Structure and Earnings Inequality, in: Ashenfelter, O. and D. Card, Handbook of Labor Economics, 3A, Ch. 26, Elsevier.

[4] Autor, D., L. Katz and M. Kearney, 2005, Rising Wage Inequality: The Role of Composition and Prices, NBER working paper \# 11628.

[5] Booth, A., M. Francesconi, and J. Frank, 2003, A Sticky Floors Model of Promotion, Pay, and Gender, European Economic Review, 47: 295-322.

[6] Frydman, C., 2005, Rising Through the Ranks: The Evolution of the Market for Corporate Executives, 1936-2003, Working Paper, MIT Sloan School of Management. 
[7] Gautier, P., 2002, Unemployment and Search Externalities in a Model with Heterogeneous Jobs and Workers, Economica, 69: 21-40.

[8] Hall, B. J., and K. J. Murphy, 2003, The Trouble with Stock options, Journal of Economic Perspectives, 17: 49-70.

[9] Lucas, R. E., 1978, On the Size Distribution of Business Firms, The Bell Journal of Economics, 9: 508-523.

[10] Murphy, K. J., 1999, Executive Compensation, in Ashenfelter, O. and D. Card, 1999, Handbook of Labor Economics, 3B, Ch. 38, Elsevier

[11] Murphy, K. J. and J. Zábojník, 2004, CEO Pay and Appointments: A Market-Based Ecplanation for Recent Trends", American Economic Review, Papers and Proceedings, 192-196.

[12] Murphy, K. J. and J. Zábojník, 2007, Managerial Capital and the Market for CEOs, Working paper, University of Southern Clifornia

[13] OECD, 2007, Employment Outlook

[14] Piketty, T., and E. Saez, 2006, The Evolution of Top Incomes: A Historical and International Perspective, American Economic Review, Papers and Proceedings, 96: 200-205.

[15] Pissarides, C. A., 1994, Search Unemployment with On-the-job Search, The Review of Economic Studies, 61: 457-475.

[16] Rosen, S., 1982, Authority, Control and the distribution of Earnings, The Bell Journal of Economics, 11: 311-323.

\section{Appendix}

\subsection{Appendix 1: Proof of Proposition 1}

Proof. We derive the different wages of each type of workers in different jobs. Consider first the wage of a low-educated worker employed in nonmanagement. Using equation (6), we can rewrite the payoff of as

$$
W_{L N}=\frac{w_{L N}+s E_{L}+p_{L M} W_{L M}}{r+s+p_{L M}} .
$$


Similarly, using equation (8) the disagreement payoff of a low-skilled worker bargaining for a non-management job is

$$
D_{L N}=\frac{s E_{L}+p_{L M} W_{L M}}{r+s+p_{L M}}
$$

The expected profit from recruiting a low-skilled worker to a non-management job is given by equation (2). This can be rewritten as

$$
J_{L N}=\frac{y_{L N}-w_{L N}}{r+s+p_{L M}} .
$$

The Nash bargaining rule is given by

$$
(1-\beta)\left(W_{L N}-D_{L N}\right)=\beta J_{L N} .
$$

Substituting (12), (13), and (14) into (15), we obtain

$$
(1-\beta)\left(\frac{w_{L N}}{r+s+p_{L M}}\right)=\beta\left(\frac{y_{L N}-w_{L N}}{r+s+p_{L M}}\right) .
$$

Simplifying this expression gives

$$
w_{L N}=\beta y_{L N}=\beta y .
$$

Using similar arguments, we obtain

$$
\begin{aligned}
w_{L M} & =\beta y_{L N}=\beta \mu_{1} y, \\
w_{H N} & =\beta y_{H N}=\beta \mu_{2} y, \\
w_{H M} & =\beta y_{H M}=\beta \mu_{3} y .
\end{aligned}
$$

\subsection{Appendix 2: Deriving the steady state conditions}

Proof. We first derive the steady state conditions, which equate the flow of workers into a given job to the flow of workers out of that state. For low-educated workers the flows in and out of non-management are

$$
p_{N} e_{L}=\left(s+p_{L M}\right) i_{L N}
$$

and the flows in and out of management are

$$
p_{L M}\left(e_{L}+i_{L N}\right)=s i_{L N} .
$$


Similarly, for highly-educated employees the flows related to non-management job are

$$
p_{N} e_{H}=\left(s+p_{H M}\right) i_{H N} .
$$

Finally, the steady state condition for the flows of highly-educated workers in and out of management can be written as

$$
p_{H M}\left(e_{H}+i_{H N}\right)=s i_{H M} .
$$

Since,

$$
i_{L N}+i_{L M}+e_{L}=\pi,
$$

the following equations can be derived from (20), (21) and (24)

$$
\begin{gathered}
e_{L}=\frac{s \pi}{\left(s+p_{L M}+p_{N}\right)}, \\
i_{L M}=\frac{p_{L M} \pi}{\left(s+p_{L M}\right)}, \\
i_{L N}=\frac{s p_{N} \pi}{\left(s+p_{L M}+p_{N}\right)\left(s+p_{L M}\right)} .
\end{gathered}
$$

In a similar fashion

$$
\begin{gathered}
e_{H}=\frac{s(1-\pi)}{\left(s+p_{H M}+p_{N}\right)}, \\
i_{H M}=\frac{p_{H M}(1-\pi)}{\left(s+p_{H M}\right)} \\
i_{H N}=\frac{s p_{N}(1-\pi)}{\left(s+p_{H M}+p_{N}\right)\left(s+p_{H M}\right)} .
\end{gathered}
$$

\subsection{Appendix 3: Solving for the steady state probabil- ities}

Proof. Applying the free-entry condition $r V_{H M}=r V_{L M}=r V_{N}=0$ and substituting (19) into (4), the following equation is obtained:

$$
J_{H M}=\frac{(1-\beta) \mu_{3} y}{r+s} .
$$

We can then use (3) to derive

$$
q_{H M}=\frac{c_{H M}}{J_{H M}}=\frac{c_{H M}(r+s)}{(1-\beta) \mu_{3} y}
$$


Assuming that the matching technology is Cobb-Douglas,

$$
x_{H M}=\left(v_{H M}\right)^{\alpha}\left(e_{H}+i_{H N}\right)^{1-\alpha},
$$

we obtain

$$
\begin{aligned}
\theta_{H M} & =\left(\frac{(1-\beta) \mu_{3} y}{c_{H M}(r+s)}\right)^{1 / 1-\alpha}, \\
p_{H M} & =\theta_{H M}^{\alpha} .
\end{aligned}
$$

It then follows that

$$
v_{H M}=\left(e_{H}+i_{H N}\right) \theta_{H M}^{\alpha} .
$$

By a symmetric argument, if we assume that

$$
x_{L M}=\left(v_{L M}\right)^{\alpha}\left(e_{L}+i_{L N}\right)^{1-\alpha},
$$

we obtain

$$
\begin{aligned}
\theta_{L M} & =\left(\frac{(1-\beta) \mu_{2} y}{c_{L M}(r+s)}\right)^{1 / 1-\alpha} \\
p_{L M} & =\theta_{L M}^{\alpha} \\
v_{L M} & =\left(e_{L}+i_{L N}\right) \theta_{L M}^{\alpha} .
\end{aligned}
$$

From (2), (16), and (18) we derive

$$
J_{L N}=\frac{(1-\beta) y}{r+s+p_{L M}}, J_{H N}=\frac{(1-\beta) \mu_{1} y}{r+s+p_{H M}} .
$$

Using (25) and (26), we can compute

$$
e_{L}+e_{H}=\frac{s\left[\pi\left(p_{H M}-p_{L M}\right)+p_{L M}+s+p_{N}\right]}{\left(s+p_{H M}+p_{N}\right)\left(s+p_{L M}+p_{N}\right)},
$$

and

$$
\begin{aligned}
& \frac{e_{H}}{e_{H}+e_{L}}=\frac{(1-\pi)\left(s+p_{L M}+p_{N}\right)}{\pi\left(p_{H M}-p_{L M}\right)+p_{L M}+s+p_{N}}, \\
& \frac{e_{L}}{e_{H}+e_{L}}=\frac{\pi\left(s+p_{H M}+p_{N}\right)}{\pi\left(p_{H M}-p_{L M}\right)+p_{L M}+s+p_{N}}
\end{aligned}
$$

The vacancy condition for non-management job given by (1) can be rewritten as

$$
q_{N}\left[\left(\frac{e_{L}}{e_{H}+e_{L}}\right) J_{L N}+\left(\frac{e_{H}}{e_{H}+e_{L}}\right) J_{H N}\right]=c_{N} .
$$


By definition, $q_{N}=x_{N} / V_{N}$. It then follows that

$$
v_{N}=\left[\left(\frac{e_{L}}{e_{H}+e_{L}}\right) \frac{J_{L N}}{c_{N}}+\left(\frac{e_{H}}{e_{H}+e_{L}}\right) \frac{J_{H N}}{c_{N}}\right]^{\frac{1}{1-\alpha}}\left(e_{L}+e_{H}\right) .
$$

Hence

$$
p_{N}=\left[\left(\frac{e_{L}}{e_{H}+e_{L}}\right) J_{L N}+\left(\frac{e_{H}}{e_{H}+e_{L}}\right) J_{H N}\right]^{\frac{\alpha}{1-\alpha}} .
$$

This can be expressed as

$p_{N}=\left[\frac{\pi\left(s+p_{H M}+p_{N}\right)+(1-\pi)\left(s+p_{L M}+p_{N}\right) \mu_{1}}{\pi\left(p_{H M}-p_{L M}\right)+p_{L M}+s+p_{N}}\right]^{\frac{\alpha}{1-\alpha}}\left[\left(\frac{(1-\beta) y}{c_{N}(r+s)}\right)\right]^{\frac{\alpha}{1-\alpha}}$,

where

$$
p_{L M}=\left(\frac{(1-\beta) \mu_{2} y}{c_{L M}(r+s)}\right)^{\alpha / 1-\alpha}, p_{H M}=\left(\frac{(1-\beta) \mu_{3} y}{c_{H M}(r+s)}\right)^{\alpha / 1-\alpha} .
$$

We see that (32) can be rewritten as

$$
G\left(p_{N} ; \alpha, \mu_{1}, \mu_{2}, \mu_{3}, \beta, r, s, y, \pi, c_{N}, c_{L M}, c_{H M}\right)=0,
$$

where $G\left(p_{N} ; \alpha, \mu_{1}, \mu_{2}, \mu_{3}, \beta, r, s, y, \pi, c_{N}, c_{L M}, c_{H M}\right)$ is given by

$$
p_{N}-g\left(p_{N} ; \alpha, \mu_{1}, \mu_{2}, \mu_{3}, \beta, r, s, y, \pi, c_{N}, c_{L M}, c_{H M}\right),
$$

where $g\left(p_{N} ; \alpha, \mu_{1}, \mu_{2}, \mu_{3}, \beta, r, s, y, \pi, c_{N}, c_{L M}, c_{H M}\right)$ equals

$$
\left[\frac{\pi\left(s+p_{H M}+p_{N}\right)+(1-\pi)\left(s+p_{L M}+p_{N}\right) \mu_{1}}{\pi\left(p_{H M}-p_{L M}\right)+p_{L M}+s+p_{N}}\right]^{\frac{\alpha}{1-\alpha}}\left[\left(\frac{(1-\beta) y}{c_{N}(r+s)}\right)\right]^{\frac{\alpha}{1-\alpha}} .
$$

We next define

$$
g\left(p_{N}\right) \equiv g\left(p_{N} ; \alpha, \mu_{1}, \mu_{2}, \mu_{3}, \beta, r, s, y, \pi, c_{N}, c_{L M}, c_{H M}\right)
$$

To solve for $p_{N}$, we apply the implicit function theorem. To do so, we need to show that $G_{p_{n}} \neq 0$ in the steady state. We first compute

$$
G_{p_{n}}=1-g_{p_{N}}
$$

$g_{p_{N}}$ can be computed as

$$
\left(\frac{\alpha}{1-\alpha}\right) g\left(p_{N}\right)\left[\frac{u\left(s, p_{H M}, p_{L M}, p_{N}, \mu_{1}, \pi\right)}{v\left(s, p_{H M}, p_{L M}, p_{N}, \pi\right)}\right]^{-1} \frac{h\left(\pi, \mu_{1}, p_{H M}, p_{L M}\right)}{\left[v\left(s, p_{H M}, p_{L M}, p_{N}, \pi\right)\right]^{2}}
$$


where

$$
\begin{aligned}
v\left(s, p_{H M}, p_{L M}, p_{N}, \pi\right) & =\pi\left(p_{H M}-p_{L M}\right)+p_{L M}+s+p_{N}, \\
u\left(s, p_{H M}, p_{L M}, p_{N}, \mu_{1}, \pi\right) & =\pi\left(s+p_{H M}+p_{N}\right)+(1-\pi)\left(s+p_{L M}+p_{N}\right) \mu_{1}, \\
h\left(\pi, \mu_{1}, p_{H M}, p_{L M}\right) & =\pi(1-\pi)\left(\mu_{1}-1\right)\left(p_{H M}-p_{L M}\right) .
\end{aligned}
$$

Lemma $2 G_{p_{n}}>0$, for all $\alpha \in(0,1)$.

Proof. We can rewrite $g_{p_{N}}$ as

$$
g\left(p_{N}\right)\left(\frac{\alpha}{1-\alpha}\right) \frac{h\left(\pi, \mu_{1}, p_{H M}, p_{L M}\right)}{u\left(s, p_{H M}, p_{L M}, p_{N}, \mu_{1}, \pi\right) v\left(s, p_{H M}, p_{L M}, p_{N}, \pi\right)} .
$$

By assumption, $1<\mu_{1}$. It then follows that

$$
\frac{1}{u\left(s, p_{H M}, p_{L M}, p_{N}, \mu_{1}, \pi\right) v\left(s, p_{H M}, p_{L M}, p_{N}, \pi\right)}<\frac{1}{\left[v\left(s, p_{H M}, p_{L M}, p_{N}, \pi\right)\right]^{2}}
$$

and

Hence

$$
\left[\frac{u\left(s, p_{H M}, p_{L M}, p_{N}, \mu_{1}, \pi\right)}{v\left(s, p_{H M}, p_{L M}, p_{N}, \pi\right)}\right]^{\frac{\alpha}{1-\alpha}}<\left(\mu_{1}\right)^{\frac{\alpha}{1-\alpha}} .
$$

$$
\begin{aligned}
g_{p_{N}} & <\left(\frac{\alpha}{1-\alpha}\right)\left[\left(\frac{(1-\beta) y \mu_{1}}{c_{N}(r+s)}\right)\right]^{\frac{\alpha}{1-\alpha}} \frac{h\left(\pi, \mu_{1}, p_{H M}, p_{L M}\right)}{\left[v\left(s, p_{H M}, p_{L M}, p_{N}, \pi\right)\right]^{2}}, \\
& <\left[\left(\frac{\alpha}{1-\alpha}\right)\left(\frac{(1-\beta) y \mu_{1}}{c_{N}(r+s)}\right)\right]^{\frac{\alpha}{1-\alpha}} \frac{h\left(\pi, \mu_{1}, p_{H M}, p_{L M}\right)}{\left[v\left(s, p_{H M}, p_{L M}, p_{N}, \pi\right)\right]^{2}} .
\end{aligned}
$$

Furthermore,

$$
\left[\pi\left(p_{H M}-p_{L M}\right)+p_{L M}+s+p_{N}\right]^{2}>\left[\pi\left(p_{H M}-p_{L M}\right)\right]^{2} .
$$

Since we assumed that

we obtain

$$
\mu_{1}<\frac{(1-\alpha) \mu_{2}}{\alpha c_{L M}}
$$

$$
\begin{aligned}
g_{p_{N}} & <\left[\frac{(1-\beta) y \mu_{2}}{(r+s) c_{L M}}\right]^{\frac{\alpha}{1-\alpha}} \frac{\pi(1-\pi)\left(\mu_{1}-1\right)\left(p_{H M}-p_{L M}\right)}{\left[\pi\left(p_{H M}-p_{L M}\right)\right]^{2}} \\
& <\left[\frac{(1-\beta) y \mu_{2}}{(r+s) c_{L M}}\right]^{\frac{\alpha}{1-\alpha}} \frac{(1-\pi)\left(\mu_{1}-1\right)}{\pi\left(p_{H M}-p_{L M}\right)} \\
& =\frac{(1-\pi)\left(\mu_{1}-1\right) p_{L M}}{\pi\left(p_{H M}-p_{L M}\right)},
\end{aligned}
$$


where the last equality follows from the fact that

$$
\left(\frac{(1-\beta) y \mu_{2}}{(r+s) c_{L M}}\right)^{\frac{\alpha}{1-\alpha}}=p_{L M} .
$$

It then follows that $g_{p_{N}}<1$ if and only if $(1-\pi)\left(\mu_{1}-1\right) p_{L M}<\pi\left(p_{H M}-p_{L M}\right)$.

Since we have assumed that $\mu_{1}<2$, this inequality is always satisfied if $(1-\pi) p_{L M}<\pi\left(p_{H M}-p_{L M}\right)$, or, equivalently, if $p_{L M}<\pi p_{H M}$. This reduces to

$$
\frac{\mu_{2}}{(\pi)^{\frac{1-\alpha}{\alpha}} c_{L M}}<\frac{\mu_{3}}{c_{H M}}
$$

and consequently we have $G_{p_{n}}>0$.

A direct consequence of Lemma 2 is

$$
G_{p_{n}}=1-g_{p_{N}}\left(p_{N}\right)>0
$$

Hence we can apply the implicit function theorem to get

$$
p_{N}=f\left(\alpha, \mu_{1}, \mu_{2}, \mu_{3}, \beta, r, s, y, \pi, c_{N}, c_{L M}, c_{H M}\right) \text {. }
$$

This completes the derivations of the probabilities in the steady state. 


\subsection{Additional Regressions}

\begin{tabular}{|c|c|}
\hline & Linear regression \\
\hline Constant & $9.079(0.091)$ \\
\hline $\begin{array}{l}\text { Low-educated in non- } \\
\text { management (LNM) }\end{array}$ & - \\
\hline $\begin{array}{l}\text { Highly-educated in non- } \\
\text { management (HNM) }\end{array}$ & $0.318(0.007)$ \\
\hline $\begin{array}{l}\text { Low-educated in } \\
\text { management (LM) }\end{array}$ & $0.336(0.061)$ \\
\hline $\begin{array}{l}\text { Highly-educated in } \\
\text { management (HM) }\end{array}$ & $0.662(0.013)$ \\
\hline Year 1997 & - \\
\hline Year 1998 & $0.008(0.001)$ \\
\hline Year 1999 & $0.008(0.002)$ \\
\hline Year2000 & $0.013(0.002)$ \\
\hline Year2001 & $0.018(0.004)$ \\
\hline Year2002 & $0.014(0.006)$ \\
\hline Year2003 & $0.012(0.005)$ \\
\hline HNM*1998 & $0.004(0.003)$ \\
\hline HNM*1999 & $0.013(0.005)$ \\
\hline $\mathrm{HNM} * 2000$ & $0.023(0.006)$ \\
\hline $\mathrm{HNM} * 2001$ & $0.012(0.008)$ \\
\hline $\mathrm{HNM} * 2002$ & $-0.010(0.014)$ \\
\hline $\mathrm{HNM} * 2003$ & $0.014(0.009)$ \\
\hline LM*1998 & $0.122(0.024)$ \\
\hline LM*1999 & $0.124(0.029)$ \\
\hline $\mathrm{LM} * 2000$ & $0.118(0.046)$ \\
\hline LM*2001 & $0.179(0.061)$ \\
\hline $\mathrm{LM} * 2002$ & $0.192(0.079)$ \\
\hline LM*2003 & $0.227(0.081)$ \\
\hline HM*1998 & $0.039(0.007)$ \\
\hline HМ*1999 & $0.032(0.011)$ \\
\hline $\mathrm{HM} * 2000$ & $0.055(0.014)$ \\
\hline HM*2001 & $0.070(0.014)$ \\
\hline HM*2002 & $0.063(0.015)$ \\
\hline HM*2003 & $0.081(0.015)$ \\
\hline R-squared & 0.390 \\
\hline
\end{tabular}

Table A1. Mincer wage regression. 